\title{
The Study of Influence of Silica and Polyethilene Glycols Organic-Inorganic Compounds on Free-Radical Processes in Vitro
}

\author{
Olga G. Sitnikova ${ }^{1}$, Sergey B. Nazarov ${ }^{1}$, Irina V. Shikhanova ${ }^{2}$, Alexander V. Agafonov ${ }^{2}$, \\ Jean A. Dyuzhev ${ }^{1}$, Irina G. Popova ${ }^{1}$ \\ ${ }^{1}$ Ivanovo State Research Institute of Maternity and Childhood (RIMC), Ivanovo, Russia; ${ }^{2}$ Institute of Solution Chemistry, Russian \\ Academy of Sciences, Ivanovo, Russia. \\ Email: ivgenlab@gmail.com
}

Received July 20 $0^{\text {th }}, 2010$; revised August $10^{\text {th }}, 2010$; accepted September $30^{\text {th }}, 2010$.

\begin{abstract}
In this study investigation of influence of hybrid nanosilica-polyethylene glycols materials (molecular weight 1500, 6000 and 15000), prepared by sol-gel synthesis, on lipid peroxidation and antioxidant activity of human serum in vitro was performed. Methods included chemiluminescence analysis and quantitative malonic dialdehyde estimation. It was revealed that nanosilica-PEG materials with different molecular weight had certain biological activity. Powders of $\mathrm{SiO}_{2}-\mathrm{PEG} 1500$ and $\mathrm{SiO}_{2}-\mathrm{PEG} 6000$ manifest prooxidant effects, whereas mesoporous (calcine) powders produced antioxidant effects in blood serum in vitro.
\end{abstract}

Keywords: Free-Radical Oxidation, Nanosilica, Chemiluminescence, Malonic Dialdehyde

\section{Introduction}

The study of free-radical processes of lipid oxidation and antioxidant system is an important problem of modern biomedicine. Oxygen is a powerful oxidant and oxygen-mediated reactions are the main sources of energy for variety of biological species. Metabolic processes produce reactive oxygen species (ROSs), free radicals, peroxides, malonic dialdehyde, Schiff's bases, which damage membrane structures and lead to oxidative stress, being the causative factor for a lot of widely spread diseases, including reproductive disorders and prenatal injuries [1-3].

Concerning this the role of antioxidants is to neutralize toxic products of free-radical lipid peroxidation. In conditions of excessive peroxidation the capacity of antioxidant defense may decrease due to insufficient endogenic antioxidant production or unfavorable environment factors [3]. Various substances are known to have antioxidant activity; their investigation is of certain importance for both biology and medicine [4].

Nowadays silica compounds attract considerable attention. Silica stimulates fibroblastic activity of mesenchyma, promoting granulation and scarring. The lack of silica may lead to depression of leukocyte activity in inflammation, poor wound scarring, anorexia, pruritus, tissue flexibility decrease, skin turgor decrease, vascular permeability increase and haemorrhagia as a result. Apart from this silica antioxidant activity stands [5].

Investigators of peroxidation showed that silica powders stimulated active oxygen species and free radicals production in culture of epithelial cells, resulting in caspase activation and apoptosis [6]. Some authors experimentally found out that inhalation of crystalloid silica in animals lead to oxidative stress, inflammation and alveolar fibrosis $[7,8]$.

As a catalysts and functional composite materials special attention is attracted by matrix hybrid silica derivates. In this study we presented physical-chemical properties of silica-based materials and their influence on peroxidation processes in human serum. Silica nanoparticles are biologically inert, have high adsorption rate, thermal and mechanic stability, and therefore are expected to manifest antioxidant activity.

The aim of the work was to study the influence of organic-innorganic silica and polyethylene glycols compounds on free-radical processes in vitro. 


\section{Materials and Methods}

\subsection{Reagents for Silica Nanoparticles Synthesis}

Tetraethoxysilane (TEOS) $\left(\mathrm{C}_{2} \mathrm{H}_{5} \mathrm{O}\right)_{4} \mathrm{Si}$ (high purity grade, Ekos-1, Russia), diethylamine $\left(\mathrm{C}_{2} \mathrm{H}_{5}\right)_{2} \mathrm{NH}$ (moderate purity grade, Aldrich), polyethylene glycols $\left[-\mathrm{OCH}_{2} \mathrm{CH}_{2}-\right]_{\mathrm{n}}$ with molecular weight of 1500, 6000, 15000 (Aldrich) and rectified ethanol (96 wt\%) were used without further purification.

\subsection{Synthesis of Hybrid Organic-Inorganic $\mathrm{SiO}_{2}$-Polyethylene Glycol Materials}

The synthesis was carried out in ethanol media at temperature of $20^{\circ} \mathrm{C}$. Polyethylene glycol was dissolved in required amount of water and was added to ethanol. Than a catalyst of tatraethoxysilane hydrolysis - diethyl amine - was added. The resulting mixture was homogenized for $15 \mathrm{~min}$. After that small doses of tatraethoxysilane $(0.5-1.0 \mathrm{ml})$ were injected into the system using syringe. Total synthesis time was 17 hrs. Particles were filtered from the original solution and dried out on open air at temperature of $70-100^{\circ} \mathrm{C}$ until mass stability.

We investigated two types of hybrid organic-inorganic $\mathrm{SiO}_{2}$-PEG materials: noncalcine and calcine in muffle furnace $\left(800^{\circ} \mathrm{C}, 2 \mathrm{hrs}\right)$.

\subsection{IR Spectroscopy}

IR spectra of produced powders were recorded using Avatar 360 FT-IR ESP spectrometer (wave range: 400$4000 \mathrm{~cm}^{-1}$ ). Preliminary samples of powders were grinded with $\mathrm{KBr}$ in agate mortar and pressed in discs.

\subsection{Thermogravimetry}

Thermogravimetric measuring were performed on thermoanalythical installation. The mass of a sample was 80-90 mg. The heating was carried out from room temperature up to $1000^{\circ} \mathrm{C}$ with rate of $5^{\circ} \mathrm{C}$ per min.

\subsection{Brunauer-Emmett-Teller (BET) Surface Area Measurement}

First step of BET analysis was heating of samples to eliminate adsorbed impurities. Then argon at temperature of $77 \mathrm{~K}$ was adsorbed on materials to form a monomolecular film on accessible area. The amount of adsorbed argon served to determine the BET surface area.

In experiments we used native serum of 10 patients, administered in obstetrical or gynecological clinics of Ivanovo Research Institute of Maternity and Childhood. We decided not to use whole blood to prevent coagulation. Suspension of studied powders was added to $1 \mathrm{ml}$ of native serum, which was then incubated at $4^{\circ} \mathrm{C}$ for $1 \mathrm{hr}$.
The ratio between powders and serum was $5.0 \mathrm{~g} / \mathrm{L}$ for mesostructured (noncalcine) powder and $50.0 \mathrm{~g} / \mathrm{L}$ for mesoporous (calcine) powder. At this stage of experiments we didn't try to evaluate pharmacological doses of studied powders as the only aim of experiments was to determine any possible pro- or antioxidant properties of synthesized materials in vitro. The incubation temperature was found to limit bacterial activity. Native serum without nanomaterials stood for control. After incubation samples were centrifuged at $3000 \mathrm{rpm}$ for $10 \mathrm{~min}$. Supernatants were transferred into clean dry tubes and underwent analysis.

\subsection{Estimation of Peroxidation Intensity by Induced Chemiluminescence (CL)}

The method was based on catalytic reduction of peroxides by bivalent ferric ions. Generated free radicals acted as oxidation initiators in biological substrate. Free radicals recombination followed by photon release, which could be registered in $40 \mathrm{~s}$. This was a period of maximal intensity. We used hydrogen peroxide and ferric sulfate as biochemiluminescence inductors. $0.1 \mathrm{ml}$ of serum was mixed with $0.4 \mathrm{ml}$ phosphate buffer ( $\mathrm{pH} 7.5), 0.4 \mathrm{ml}$ ferric sulfate $(0.01 \mathrm{mM}), 0.2 \mathrm{ml} 2 \%$ hydrogen peroxide and underwent CL. Intensity of luminescence was evaluated by BHL-06M biochemiluminometer (Russia). Registered parameters were as follows (Figure 1): peak intensity of luminescense $\left(\mathrm{I}_{\max }\right)$ - the highest intensity of luminescense registered within first 40 seconds of Fenton's reaction; light sum (S) - the area under the curve of luminescent signal; slope of the curve $(\operatorname{tg} \alpha)$ - tangent of decrease signal angle.

Imax and $\mathrm{S}$ reflected potential for lipid peroxidation. Antioxidant activity was characterized by $\operatorname{tg} \alpha$ and coefficient $\mathrm{K}\left(\mathrm{I}_{\max } / \mathrm{S}\right.$ ratio $)$.

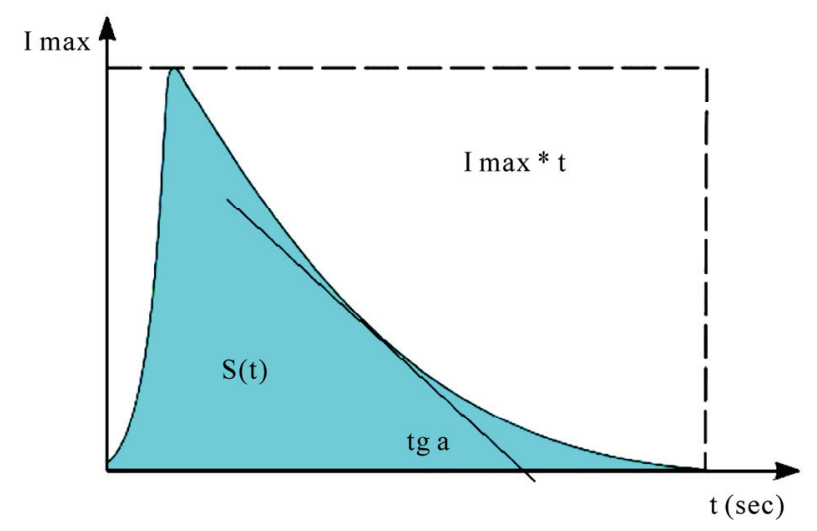

Figure 1. Typical kinetics of serum chemiluminescense. The registered parameters are as follows: peak intensity $\left(I_{\max }\right)$, light sum $(S(t))$, the slope of the curve $(\operatorname{tg} \alpha)$. 


\subsection{Malonic Dialdehyde Serum Concentration Measurement}

The method was based on reaction between malonic dialdehyde (MDA) and thiobarbituric acid [9]; the product of reaction had pink color and was identified by SF-46 spectrophotometer (Russia) on wave length 523 $\mathrm{nm}$.

\section{Results and Discussion}

Qualitative and quantitative structure of materials was investigated by IR spectroscopy and thermogravimetric analysis.

Thermograms of hybrid organic-inorganic $\mathrm{SiO}_{2}-\mathrm{PEG}$ material (molecular weight 15000) are presented on Figure 2.

Burning of polymer component from matrix $\mathrm{SiO}_{2}-\mathrm{PEG}$ 15000 hybrid is described by the peak with maximum at $291{ }^{\circ} \mathrm{C}$ on differential thermogravimetric diagram. The amount of organic phase was $39 \mathrm{wt} \%$ in sample. Water content was $13.5 \mathrm{wt} \%$. The curve of differential thermal analysis did not reveal any thermal effects.

Figure 3 shows IR spectra of hybrid organic-inorganic (a) $\mathrm{SiO}_{2}-\mathrm{PEG} 15000$ and (b) material calcined at $800^{\circ} \mathrm{C}$.

There were characteristic oscillations of $\mathrm{Si}-\mathrm{OH}$ and $\mathrm{Si}-\mathrm{O}-\mathrm{Si}$ found in spectra. Also, in areas of wavenumbers $3600-3500,1640$ and $400-200 \mathrm{~cm}^{-1}$ oscillations of adsorbed $\mathrm{H} 2 \mathrm{O}$, isolated and linked $\mathrm{OH}$ groups were found.

In spectrum of hybrid organic-inorganic $\mathrm{SiO}_{2}-\mathrm{PEG}$ 15000 oscillations of alkyl $\mathrm{CH}_{3}, \mathrm{CH}_{2}$ and $\mathrm{CH}$ groups [10-19] proved the presence of organic phase in composite.

Intensive flat halo on X-ray diagram of hybrid $\mathrm{SiO}_{2}$ PEG 15000 material reflected its amorphism (Figure 4).

Results of sedimentation gave data on morphology of hybrid material powders. Sizes of particles of hybrid $\mathrm{SiO}_{2}$-PEG composite determined by sedimentation before and after calcining were (Figure 5) as follows. Hybrid material: $2-300 \mu \mathrm{m}$, with the prevalence of 24 and $150 \mu \mathrm{m}$ fractions; tempered material: 2-110 $\mu \mathrm{m}$, with modal size $28 \mu \mathrm{m}$. Specific areas of noncalcine and calcine hybrid organic-inorganic $\mathrm{SiO}_{2}$-PEG 15000 material powders were discovered by thermal desorption of argon (Table 1).

Thus, there were synthesized two groups of composite materials with different structure: organic-inorganic compounds with amorphous structure and mesostructural materials with system of ordered mesochannels, filled by molecular organic templates. All materials were calcined at $800^{\circ} \mathrm{C}$ for creating of high-porous silica specimens with the same structural features as their noncalcine ancestors. Investigation of pro- and antioxidant properties

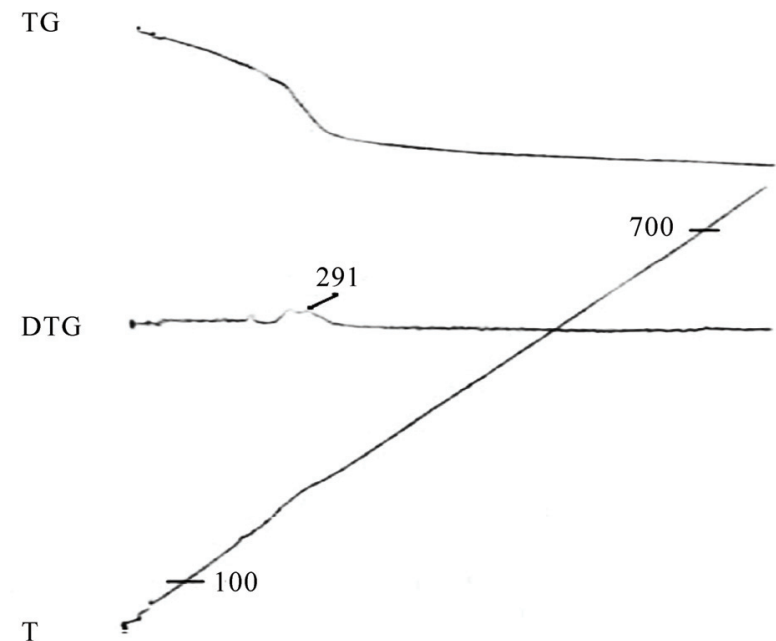

Figure 2. Thermograms of hybrid organic-inorganic $\mathrm{SiO}_{2}-$ PEG 15000 material.

Table 1. Specific surface areas of hybrid SiO2-PEG 15000 and calcined at $800{ }^{\circ} \mathrm{C}$ materials.

\begin{tabular}{cc}
\hline Material & $\begin{array}{c}\text { Specific surface area by } \\
\mathbf{B E T}, \mathbf{~}^{2} / \mathbf{g}\end{array}$ \\
\hline $\mathrm{SiO}_{2}$-PEG 15000 (noncalcine) & 91 \\
$\mathrm{SiO}_{2}$-PEG 15000 (calcine) & $>800$ \\
\hline
\end{tabular}

of these powders was carried out in vitro.

Biochemical study revealed different influence of investigated powders on intensity of peroxidation in human serum (Tables 2 and 3). Parameters of chemiluminescence revealed in native serum were estimated as $100 \%$.

Adding of $\mathrm{SiO}_{2}$-PEG powders with molecular weight 1500 and 6000 to experimental system lead to increased chemiluminescence, which proved high ROS and free radical ( $\mathrm{R}-, \mathrm{OH}-, \mathrm{RO}-, \mathrm{RO}_{2^{-}}, \mathrm{O}_{2^{-}}$) production in Fenton's reaction [20,21]. Recombination of radicals formed unstable tetraoxide, which disintegrated with photon emission and raised lightsum $\mathrm{S}$ (plus 23\%, $\mathrm{p}=0.0081$ and $18 \%, \mathrm{p}=0.0131$, comparing with controls, respectively for 1500 and 6000 powders), fast flash $\mathrm{I}_{\max }$ (plus $26 \%$, p $=0.0459$ for 1500 powder). Investigation of $\mathrm{SiO}_{2}-\mathrm{PEG}$ with molecular weight 15000 didn't reveal any significant CL changes. Study of mesoporous (calcine) $\mathrm{SiO}_{2}-$ PEG powder revealed its antioxidant activity, which was developed by decreasing of peroxidation processes intensity in Samples 3 and 5 (Table 3). We found increasing of $\operatorname{tg} \alpha$ (plus $15 \%, \mathrm{p}=0.0510$ ) and decreasing of MDA. The conclusion was that nanosilica-PEG compounds with different molecular weight possessed specific oxidant and antioxidant activity. $\mathrm{SiO}_{2}$-PEG 1500 and $\mathrm{SiO}_{2}$-PEG 6000 powders lead to activation of free-radical oxidation, 


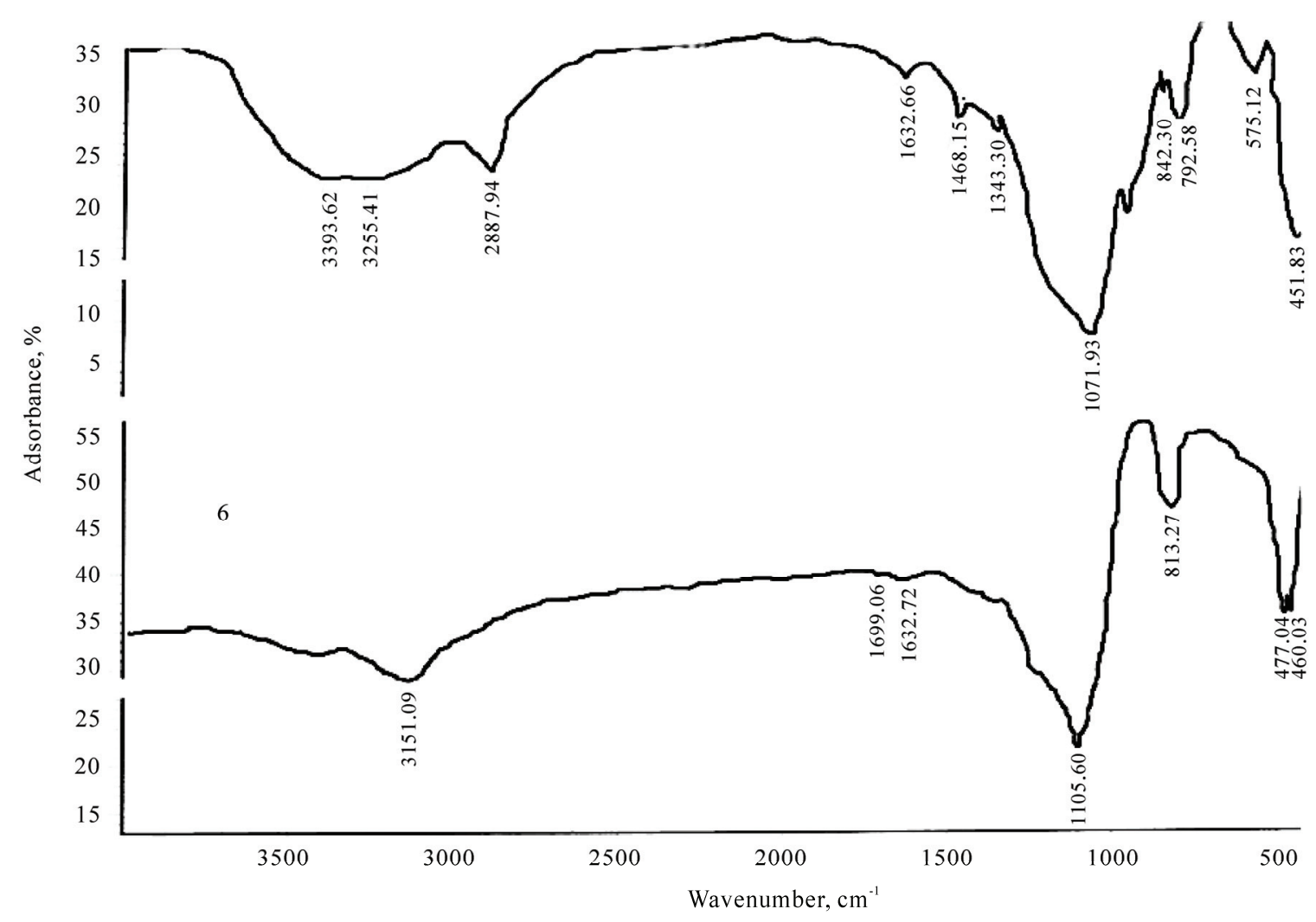

Figure 3. IR spectra of noncalcine (a) and calcine (b) hybrid organic-inorganic SiO2-PEG 15000 materials.

Table 2. Parameters of peroxidation (MDA) and induced chemiluminescence in blood serum after adding of mesostructured (noncalcine) $\mathrm{SiO}_{2}$-PEG powders $(5 \mathrm{mg} / \mathrm{mL})$ with different molecular weight $(\mathrm{M})$.

\begin{tabular}{ccccc}
\hline Parameters & Statistics $\mathbf{n}=\mathbf{5}$ & $\mathbf{M}=\mathbf{1 5 0 0}$ & $\mathbf{M}=\mathbf{6 0 0 0}$ & $\mathbf{M = 1 5 0 0 0}$ \\
\hline MDA, \% & $\mathrm{M} \pm \mathrm{m}$ & $102.67 \pm 21.40$ & $86.67 \pm 8.69$ & $98.33 \pm 10.81$ \\
$\mathrm{~S}, \%$ & $\mathrm{M} \pm \mathrm{m}$ & $123.00 \pm 2.08^{* *}$ & $118.00 \pm 2.08^{* *}$ & $102.0 \pm 8.39$ \\
$\mathrm{I}_{\max } \%$ & $\mathrm{M} \pm \mathrm{m}$ & $126.00 \pm 5.77^{*}$ & $115.33 \pm 8.69$ & $105.33 \pm 10.91$ \\
$\operatorname{tg} \alpha, \%$ & $\mathrm{M} \pm \mathrm{m}$ & $95.67 \pm 4.48$ & $110.33 \pm 4.06$ & $103.00 \pm 13.20$ \\
$\mathrm{~K}, \%$ & $\mathrm{M} \pm \mathrm{m}$ & $92.33 \pm 4.33$ & $97.33 \pm 3.38$ \\
\hline
\end{tabular}

Note: Here and further asterix reflects significant differences among estimated groups $(* \mathrm{p}<0,05 ; * * \mathrm{p}<0,01)$.

Table 3. Parameters of peroxidation (MDA) and induced chemiluminescence of blood serum after adding of mesoporous (calcine) $\mathrm{SiO}_{2}$-PEG powders $(50 \mathrm{mg} / \mathrm{mL})$ with different molecular weight $(\mathrm{M})$.

\begin{tabular}{cccccccc}
\hline \multirow{2}{*}{ Parameters } & \multirow{2}{*}{ Statistics n $=\mathbf{5}$} & \multicolumn{2}{c}{$\mathbf{M}=\mathbf{1 5 0 0}$} & \multicolumn{2}{c}{$\mathbf{M = 6 0 0 0}$} & \multicolumn{2}{c}{$\mathbf{M}=\mathbf{1 5 0 0 0}$} \\
\cline { 3 - 9 } & & $\mathbf{1}$ & $\mathbf{2}$ & $\mathbf{3}$ & $\mathbf{4}$ & $\mathbf{5}$ & $\mathbf{6}$ \\
\hline $\mathrm{MDA}, \%$ & $\mathrm{M} \pm \mathrm{m}$ & $94.60 \pm 9.49$ & $86.60 \pm 6.98$ & $89.00 \pm 7.77$ & $93.20 \pm 10.54$ & $89.60 \pm 3.79^{*}$ & $100.20 \pm 4.10$ \\
$\mathrm{~S}, \%$ & $\mathrm{M} \pm \mathrm{m}$ & $97.80 \pm 3.69$ & $93,00 \pm 6.89$ & $103.80 \pm 3.62$ & $98.40 \pm 6.27$ & $96.10 \pm 1.91$ & $109.80 \pm 5.19$ \\
$\mathrm{I}_{\max }, \%$ & $\mathrm{M} \pm \mathrm{m}$ & $104.80 \pm 5.80$ & $103.00 \pm 8.96$ & $111.20 \pm 8.73$ & $103,40 \pm 12.86$ & $98.20 \pm 7.68$ & $150.50 \pm 29.70$ \\
$\operatorname{tg} \alpha, \%$ & $\mathrm{M} \pm \mathrm{m}$ & $116,80 \pm 9.73$ & $128.60 \pm 15.41$ & $115.20 \pm 5.17^{*}$ & $114.20 \pm 17.11$ & $112.80 \pm 4.64^{*}$ & $173.25 \pm 43.16$ \\
$\mathrm{~K}, \%$ & $\mathrm{M} \pm \mathrm{m}$ & $100,40 \pm 2.79$ & $109.00 \pm 2.65^{*}$ & $99.20 \pm 1.83$ & $99.60 \pm 6.02$ & $94.20 \pm 2.48$ & $120.00 \pm 22.76$
\end{tabular}

Note: Numbers 1, 2, 3, 4, 5, 6 stands for different preparations of mesoporous (calcine) $\mathrm{SiO}_{2}$-PEG with different molecular weight $(1500,6000,15000)$. 


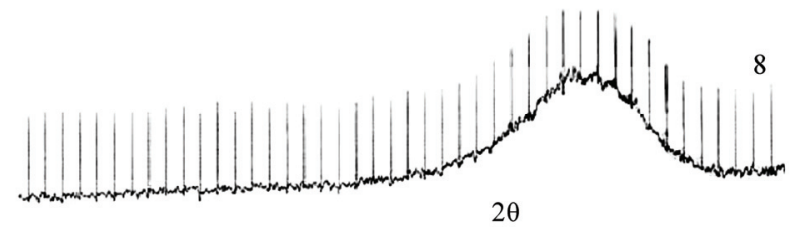

Figure 4. X-ray diagram of hybrid organic-inorganic $\mathrm{SiO}_{2}$ PEG 15000 material.

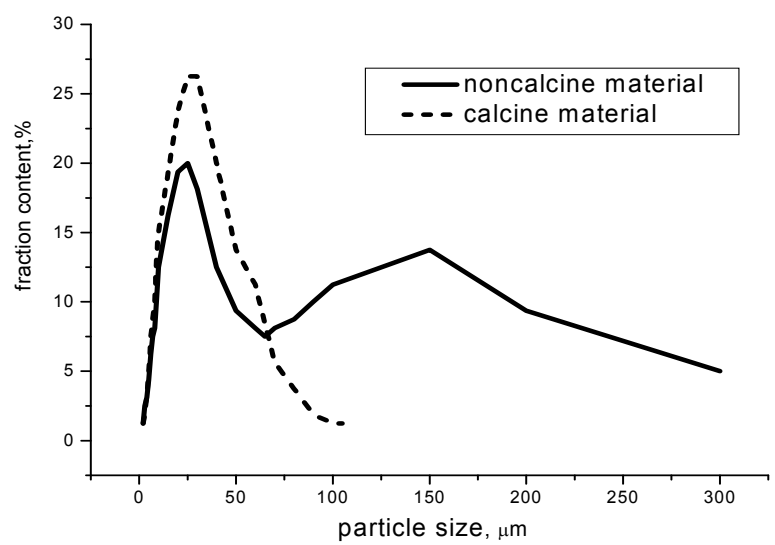

Figure 5. Particle size distribution in noncalcine and calcine hybrid organic-inorganic $\mathrm{SiO}_{2}$-PEG 15000 materials.

whereas mesoporous (calcine) materials with molecular mass 6000 and 15000 manifested antioxidant properties in human serum due to their large specific surface area ( $>$ $800 \mathrm{~m}^{2} / \mathrm{g}$ ). These findings can be useful for creating of pharmacological preparations.

\section{REFERENCES}

[1] V. Z. Lankin, A. K. Tikhadze and Y. N. Belenkov, "Free-Radical Processes in Cardiovascular Diseases," Kardiologiya, Vol. 40, No. 7, 2000, pp. 48-61. (in Russian).

[2] J. Fujii, Y. Iuchi and F. Okada, "Fundamental Roles of Reactive Oxygen Species and Protective Mechanisms in the Female Reproductive System," Reproductive Biology and Endocrinology, No. 3, 2005, p. 43.

[3] V. A. Terekhina and Y. A. Petrovich, "Free-radical Oxidation and Antioxidant system," Proper Economic Resource Management, 2005, p. 69 (in Russian).

[4] A. P. Golikov, P. P. Golikov and V. B. Davydov, "Influence of Mexidol on Oxidative Stress in Cerebral Form of Hypertensic Crisis," Kardiologiya, Vol. 42, No. 3, 2002, pp. 25-29. (in Russian).

[5] L. A. Mansurova, O. V. Fedchishin, V. V. Trofimov, T. G. Zelenina and L. E. Smolyanko, "Physiological Role of Silicium," Sibirskiy Meditsinskiy Zhurnal, No. 7, 2009, pp. 16-18. (in Russian).

[6] H.-M. Shen, Z. Zhang, Q.-F. Zhang and C.-N. Ong, "Re- active Oxygen Species and Caspase Activation Mediate Silica-Induced Apoptosis in Alveolar Macrophages," American Journal of Physiology Lung Cellular and Molecular Physiology, Vol. 280, No. 1, 2001, pp. 10-17.

[7] E. G. Barrett, C. Johnston, G. Oberdörster and J. N. Finkelstein, "Silica-Induced Chemokine Expression in Alveolar Type Ii Cells Is Mediated by Tnf-induced Oxidant Stress," American Journal of Physiology Lung Cellular and Molecular Physiology, Vol. 276, No. 6, 1999, pp. 979-988.

[8] M. Ding, X. Shi, Y. J. Lu, C. Huang, S. Leonard, J. Roberts, et al., "Induction of Activator Protein-1 through Reactive Oxygen Species by Crystalline Silica in JB6 Cells," Journal of Biological Chemistry, Vol. 276, No. 12, 2001, pp. 9108-9114.

[9] M. Ishihara, "Studies on Lipoperoxide of Normal Pregnant Women and Patient Toxemia of Pregnancy," Clinica Chimica Acta, Vol. 84, No. 1-2, 1978, pp. 1-9.

[10] R. Stangl, W. Platzer and V. Wittwer, "IR Emission Spectroscopy of Silica Aerogel," Journal of Non-Crystalline Solids, Vol. 186, 1995, pp. 256-263.

[11] M. A. S. Pedroso, M. L. Dias and C. Azuma, and C. G. Mothe, "Hydrocarbon Dispersion of Nanospherical Silica by Sol-Gel Process. 1. Tetraethoxysilane Homopolymerization," Colloid and Polymer Science, Vol. 278, No. 12, 2000, pp. 1180-1186.

[12] R. Urlaub, U. Posset and R. Thull, "FT-IR Spectroscopic Investigations on Sol-gel-derived Coatings from AcidModified Titanium Alkoxides," Journal of Non-Crystalline Solids, Vol. 256, 2000, pp. 276-284.

[13] R. L. Derosa and J. A. Trapasso, "Poly(Ethylene Glycol) Interactions with Alumina and Silica Powders Determined via DRIFT," Journal of Materials Science, Vol. 37, No. 6, 2002, pp. 1079-1082.

[14] B. Lee, Y. Kim, H. Lee and J. Yi, "Synthesis of Functionalized Porous Silicas via Templating Method as Heavy Metal Ion Adsorbents: The Introduction of Surface Hydrophilicity onto the Surface of Adsorbents," Microporous and Mesoporous Materials, Vol. 50, No. 1, 2001, pp. 77-90.

[15] H. S. Mansur, W. L. Vasconcelos, R. F. S. Lenza, R. L. Orefice, E. F. Reis and Z. P. Lobato, "Sol-Gel Silica Based Networks with Controlled Chemical Properties," Journal of Non-Crystalline Solids, Vol. 273, No. 1-3, 2000, pp. 109-115.

[16] X. Li and T. A. King, "Spectroscopic Studies of Sol-Gel-Derived Organically Modified Silicates," Journal of Non-Crystalline Solids, Vol. 204, No. 3, 1996, pp. 235-242.

[17] S.-H. Rhee, J.-Y. Choi and H.-M. Kim, "Preparation of a Bioactive and Degradable Poly( $\varepsilon$-caprolactone $) /$ silica Hybrid through a Sol-gel Method," Biomaterials, Vol. 23, No. 24, 2002, pp. 4915-4921.

[18] J. Gallardo, A. Duran, D. Di Martino and R. M. Almeida, "Structure of Inorganic and Hybrid $\mathrm{SiO}_{2}$ Sol-Gel Coatings Studied by Variable Incidence Infrared Spectros- 
copy," Journal of Non-Crystalline Solids, Vol. 298, No. 2-3, 2002, pp. 219-225.

[19] V. A. Maroni and S. J. Epperson, "An in Situ Spectroscopic Investigation of the Pyrolysis of Ethylene Glycol Encapsulated in Silica Solidate," Vibrational Spectroscopy, Vol. 27, No. 1, 2001. pp. 43-51.

[20] A. I. Zhuravlev and A. I. Zhuravleva, "Hiperweak Lumi- nescence of Blood Serum and its Role in Complex Diagnostics," Meditsina Press, Moscow, 1976. (in Russian).

[21] E. I. Kuzmina, A. S. Nelubin and M. K. Schennikova, "Application of Induced Chemiluminescence for FreeRadical Processes Estimation in Biological Substrates," In: Biokhimiya i biofizika, Gorkiy, 1983, pp. 179-183. (in Russian). 